\title{
Análise Espectromorfológica da Paisagem Sonora em Five Places to Remember de Fernando Iazzetta
}

\author{
Spectromorphological Analysis of Sound Landscape in Five Places to \\ Remenber by Fernando Iazzetta
}

\author{
Luzilei Aliel \\ Universidade de São Paulo
}

\begin{abstract}
Resumo: Este trabalho é dedicado à análise da série de obras Five Places to Remember do compositor/pesquisador Fernando Iazzetta. A série possui cinco trabalhos, entretanto, nos dedicamos a analisar três deles: Praga, Paraty, Bruxelas (as obras podem se visualizadas em: https://soundcloud.com/iazzetta). Devido às características estéticas dos trabalhos relacionados à paisagem sonora, discutimos algumas propriedades desse tipo de manifestação que procuramos entrelaçar com o trabalho analisado. Utilizamos como levantamento bibliográfico para análise, a espectromorfologia, em conjunto com os desenvolvimentos propostos por Coelho de Souza (2013). Duas características foram relevantes: 1) Marcadores de Som Transmutados - conceito proposto a partir da proposta de marcação sonora (soundmarks) (Schafer, 1977), onde os pontos de referência da paisagem sonora são drasticamente alterados por ferramentas eletroacústicas, permitindo a geração de novos materiais mantendo a organização macro. 2) Processo Rítmico Eletroacústico - O conceito gira em torno do uso de estratégias técnicas da música eletroacústica para desenvolver parâmetros rítmicos complexos.
\end{abstract}

Palavras-chave: espectromorfologia; paisagem sonora; música eletroacústica; música brasileira; Fernando Iazzetta

Abstract: This article is dedicated to the analysis of the series of works Five Places to Remember by the composer/researcher Fernando Iazzetta. The series has five works but we chose to analyze only three of them: Prague, Paraty and Brussels. Due to the aesthetic characteristics of works related to the soundscape concept, we discuss some properties of this kind of manifestation and try to intertwine it with the work analyzed. We used as a bibliographic survey for analysis the spectromorphology in conjunction with the developments proposed by Coelho de Souza (2013). Two characteristics were relevant: 1) TransmutedSound Markers concept proposed from the proposed soundmarks (Schafer, 1977), where soundscape referencial points are drastically altered by electro-acoustic tools, allowing the generation of new materials while maintaining macro organization. 2) Electroacoustic Rhythmic Process - The concept revolves around the use of technical strategies of electroacoustic music to develop complex rhythmic parameters. 
MUSICA THEORICA Revista da Associação Brasileira de Teoria e Análise Musical 2019,

v. 4, n. 2, p. 182-207 - Journal of the Brazilian Society for Music

Keywords: spectromorphology; sound landscape; electroacoustic music; Brazilian music; Fernando Iazzetta

\section{Introdução}

Five Places to Remember (FPtoR) é uma série de obras eletroacústicas produzidas em 2008 pelo compositor/pesquisador Fernando Iazzetta. Ao todo foram produzidas cinco peças: Praga, Berlim, Bogotá, Paraty e Bruxelas. Nesta análise utilizamos apenas três das cinco peças: Paraty, Bruxelas e Praga. As peças utilizam o processo de representação imaginária de um local existente. A referência à lembrança proposta no título, reflete de modo geral a construção de todas as obras. Embora FPtoR possua características estéticas de composição eletroacústica, ela se propõe como uma forma de paisagem sonora.

Embora o termo seja amplamente divulgado, não há uma definição única do que seja exatamente uma paisagem sonora. Há questionamentos sobre a própria cunhagem do termo, geralmente atribuída a Murray Schafer (1977), pois alguns pesquisadores o creditam a Southworth (1969). Entretanto, Schafer definiu o que compreendemos hoje da paisagem sonora como uma área acadêmica. Schafer, integrou o World Soundscape Project, preocupando-se principalmente com o campo da ecologia acústica. Suas premissas consistiam em dividir as paisagens sonoras em mais ou menos ruidosas, o que denominou $\mathrm{Hi}$ Fi e Lo-Fi. Áreas campestres, rurais ou isoladas eram consideradas $\mathrm{Hi}$-Fi, ou seja, com baixos índices de ruído, enquanto áreas urbanas e afins eram altamente ruidosas, sendo consideradas $L o-F i$.

Schafer (1977), no entanto, nunca definiu claramente o que era uma paisagem sonora, apenas buscou demonstrar como ela operava em um quadro quotidiano. Truax foi o primeiro autor a propor uma definição mais precisa:

[Paisagem sonora seria] um ambiente de som (ou ambiente sonoro) com ênfase na forma como ele é percebido e compreendido pelo indivíduo, ou por uma sociedade (Truax 2001).

Truax propõe, desta forma, um foco no ouvinte e não no ambiente, enfatizando o indivíduo e o contexto social, em um mesmo patamar. Sua proposta é que a percepção seja a ferramenta pela qual são determinadas as características singulares de cada paisagem sonora, resultando em um estado de confluência entre indivíduo e meio ambiente. Sobre uma perspectiva similar, 
Schafer concentrou-se indiretamente sobre a percepção das pessoas dentro do ambiente sonoro. Seu principal objetivo tinha relação com a gravação de sons que poderiam vir a ser extintos, explorando conceitos do som como um elemento intrínseco de uma paisagem.

Payne et al. (2009), escrevendo para D.E.F.R.A, ${ }^{1}$ propôs um novo resumo sobre a pesquisa acústica em paisagens sonoras.

O termo "paisagens sonoras" é por vezes considerado uma adaptação do termo visual de 'paisagens' (Schafer 1977), transferindo o foco do visual para o ambiente sonoro. Atualmente não há concordância entre as definições de soundscapes, mas o trabalho para uma definição tem sido reportado como: paisagens sonoras são a totalidade de todos os sons dentro de um local com ênfase nas relações entre a percepção do indivíduo ou sociedade, compreendendo a interação com o ambiente sonoro. Esta definição baseia-se nas definições originais de paisagem sonora e descrições da paisagem (Schafer 2001; Truax 2002). Paisagens Sonoras podem ser estudadas em uma estância micro (local, indivíduo, por exemplo: parque urbano, rua, quarto), meso (área pequena, por exemplo: área residencial, grande centro comercial) ou ao nível macro (grande área, por exemplo, toda cidade) (Payne et al. 2009).

Uma revisão bibliográfica que verse sobre ecologia sonora tenderá a citar ou relatar os avanços na área dando ênfase primária em paisagens sonoras à contribuição de R. Murray Schafer (1977) e do Projeto Mundial Soundscape (WSP). Apesar de haver hoje diversas obras substantivas nesta área, Schafer ainda é o maior contribuinte para o estabelecimento, compreensão, ensino e emancipação das paisagens sonoras. A composição de paisagens sonoras concentra-se principalmente no material sonoro. A princípio, Schafer relacionou uma associação das palavras "paisagem" (landscape) e "som" (sound) em soundscape (paisagem sonora). Este tipo de produto artístico prima pela inclusão de material sonoro inicialmente considerado como "não-musical" na criação musical contemporânea (Keller, 2004), bem como a classificação de qualquer meio físico como possível gerador espontâneo de sons (Schafer, 2001). Paisagens sonoras são geradas por múltiplas fontes sonoras, que podem ser representadas como agentes externos de um sistema aberto e complexo que apresenta propriedades emergentes de auto-organização de significado sonoro. O trabalho de Schafer embora tenha uma premissa ecológica, abrange diversas áreas: arte, música, acústica, ciências sociais, psicologia, saúde ambiental e design arquitetônico.

\footnotetext{
${ }^{1}$ Department for Environment, Food and Rural Affairs.
} 
MUSICA THEORICA Revista da Associação Brasileira de Teoria e Análise Musical 2019,

Uma das principais críticas ao trabalho de Schafer (Schulte-Fortkamp; Fiebig 2006) é a proposta de colocar o ambiente "tranquilo" e rural em um pedestal acima de outros ambientes. Para Schafer a paisagem sonora da cidade é compreendida como desfavorável e até mesmo nociva. Seu desgosto por este tipo de paisagem é relatado diversas vezes em seus escritos. Embora tais textos tenham teor acadêmico, Schafer compõe uma narrativa incomum ao universo acadêmico, considerando diferentes fontes para sua retórica, exemplos como a Bíblia, a antropologia, gravações de sons, mapas e gráficos são encontrados em seus escritos, que por fim acabam por ignorar a complexidade e as multifaces da paisagem sonora como um todo.

Aquém desta questão, seu trabalho no WSP foi substituído por Barry Truax, que publicou em 1984, (revisado em 2001) o livro Acoustic Communication, compêndio onde introduz um vocabulário acadêmico mais detalhado e específico para a discussão das paisagens sonoras:

Eu tentei no meu livro Acoustic Communication oferecer à área uma base intelectual. Essa base pode ser entendida como uma dupla crítica, primeiramente às disciplinas tradicionais que estudam algum aspecto do som, e em segundo, às ciências sociais interdisciplinares dos estudos de comunicação. A última crítica é baseada simplesmente no que considero ser um "ponto cego" na área das ciências sociais sobre qualquer assunto envolvendo percepção (Truax 2001).

Especificamente ao tratarmos do termo "paisagem sonora", este foi relatado primeiramente nos estudos de Michael Southworth (1969, apud Payne et al. 2009). Southworth investigou a questão "multissensorial" em antagonismo às experiências "monosensoriais", e sugere a ideia do que Schafer iria chamar de "soundmarks": ou seja, áreas que eram identificáveis unicamente a partir da sua paisagem sonora. Especificamente sobre as "marcações sonoras", iremos observar na análise de FPtoR, características semelhantes. Southworth propõe desta forma, um olhar para o design multissensorial, sendo este mais eficaz, no contexto ambiental, do que focarmos em qualquer modalidade sensorial individual. Para Southworth a cidade não abre espaço para tornar notáveis as nuances sonoras de sua complexidade, limitando grande parte de seu conteúdo aos sons com maior grau de prevalência. Por exemplo: os sons mais prevalentes, como do tráfego ou o de pessoas, comunica o conteúdo menos valioso da informação, entretanto, demanda mais atenção. Eles mascaram os sons 
informativos que são geralmente mais fracos e menos frequentes. (Southworth 1969, p. 56).

As pesquisas contemporâneas na área de paisagens sonoras em grande parte foram influenciadas pelo trabalho de Schafer, entretanto suas considerações qualitativas de que áreas rurais teriam uma prevalência sobre áreas urbanas lhe trouxeram questionamentos e críticas que acabam por desvalorizar seu trabalho. De fato, o principal foco de mudança da pesquisa moderna em paisagens sonoras, que iria se tornar a área conhecida como ecologia sonora, veio dos questionamentos sobre o paradigma dos sons urbanos e sons rurais (Truax; Barret 2011; Schafer 1977; Westerkamp 2002). Várias destas pesquisas buscaram questionar a relevância sobre as áreas urbanas como um local de pesquisa, além da preocupação com a recuperação da cidade como um local sonoramente agradável. Arquette (2004) aponta que sonoramente uma cidade não existiria se espelhado em um local agrário. A autora ainda questiona a taxonomia dos sons desenvolvida por Schafer, ou seja, faz crítica às relações entre sons naturais e/ou sons produzidos pelos homens. Nas palavras da autora:

Sobre as minhas dúvidas sobre as descrições de Schafer sobre ambientes urbanos, gostaria de afirmar que o ambiente sonoro, por todo o seu ambiente compactado de baixas frequências, não alcançou um nível de saturação pelo qual nos tornamos alienados dele. Em vez disso, o isolamento ou deslocamento a partir de um ambiente acústico tem uma maior extensão, alcançado devido a aparelhos como o walkman ou os telefones celulares (Arquette 2004, p. 163).

Arquette argumenta que, em contraste com a perspectiva ecologista de Schafer, o que seria crucial na discussão sobre a pesquisa em paisagens sonoras é o enfoque nos fatores que fazem o indivíduo se conectar e associar familiaridade ao conteúdo sonoro dos locais. Schafer possui uma perspectiva onde as paisagens sonoras são julgadas como mais agradáveis quando o contato humano é menor ou nulo. Para Arquette, o walkman e telefones celulares entre outros dispositivos móveis são exemplos de contribuintes à alienação, considerando que as pessoas criam seus próprios espaços privatizados, ignorando as sonoridades de um ambiente maior. Estas críticas aos dispositivos móveis e alienação sonora não parecem condizer com trabalhos em criatividade musical (Keller 2012), ecocomposição (Barreiro; Keller 2004), comprovisações (Aliel 2017) e música ubíqua. 


\section{Referencial Metodológico: Espectromorfologia}

Começaremos com algumas descrições metodológicas necessárias para analisar o FPtoR. Em geral, usaremos as propostas de Denis Smalley, a espectromorfologia, com notas que podem contribuir para este trabalho. Embora a publicação original seja de 1995, utilizaremos Smalley (1997), que é uma versão revisada. Segundo o autor, a espectromorfologia seria uma ferramenta para descrever e analisar a experiência auditiva. As duas terminologias (espectro/morfologia) se referem à interação entre o som espectral e sua transformação no tempo. Nessa abordagem, portanto, o objetivo é desenvolver uma estrutura para entender relações e comportamentos estruturais como experimentos no fluxo temporal de obras musicais. Smalley também aponta que o modelo espectromorfológico não é um método de composição, mas pode, em algum nível, contribuir para auxiliar neste processo

Em geral, são utilizadas três fontes principais de notação eletroacústica (Smalley, 1997):

1. Notação pretendida pelo artista (obra mista ou eletrônica ao vivo): contendo, materiais gráficos (partituras), instruções ou transcrições de material acústico.

2. Notação de realização: possui conteúdo técnico, como gravação, edição e organização. Pode incluir notas ou planos do compositor.

3. Notação de difusão: inclui informações sobre representação sonora, esboços de especialização ou representação de comportamento sonoro.

No entanto, esses tipos de material não permitem uma análise detalhada das consequências sônicas nos trabalhos eletroacústicos. Para Smalley, as consequências eletroacústicas estão associadas a comportamentos sonoros em relação ao gesto que causa o resultado. Ou seja, a partir de um resultado sólido, podemos induzir a fonte gestual e, portanto, gerar outro padrão causado pelo gesto inicial. Esse tipo de referência requer outra condição para a escuta. Partindo do pensamento de Pierre Schaffer (1966, p. 270) sobre escuta reduzida, ${ }^{2}$ Smalley dedica-se a dialogar com essa teoria e expandi-la por outras propriedades, como

\footnotetext{
2 Segundo Chion, a escuta reduzida é "a atitude de escutar que consiste em ouvir o som por si só, como um objeto sonoro, removendo sua fonte real ou suposta o significado que ele pode transmitir" (Chion 1983, p. 33).
} 
gesto e espaço, por exemplo. No entanto, essas características requerem assistência além da percepção auditiva. $\mathrm{O}$ autor projeta, assim, uma leitura dos eventos das obras eletroacústicas por meio de sonogramas. Essa condição, portanto, considerará características intrínsecas quando relacionada à espectromorfologia. "O objetivo é descrever os eventos sonoros e suas relações por meio da leitura e da audição, no entanto, uma obra musical não é um artefato autônomo fechado" (Smalley 1997), permitindo diversos tipos de análises envolvendo questões culturais e organizações em outras formas dialéticas.

\subsection{Notas sobre Espectromorfologia}

Inicialmente, é importante relatar que algumas traduções dos termos foram adaptadas do texto original buscando estabelecer associações com a forma proposta por Smalley e as nomenclaturas utilizadas de maneira prática em países de língua portuguesa. Dissonâncias podem ocorrer com outras literaturas portuguesas, mas estamos procurando recursos capazes de oferecer material analítico para FPtoR.

Partindo do conceito de que todo som surge de algum lugar, se sustenta, se estende ao longo do tempo e desaparece, Smalley determinará sua abordagem de como perceber e descrever ações sonoras, sendo que três sessões são preponderantes: início (onset), continuação (continuant), término (termination). O autor também aponta para o fato de que não há um ponto específico apropriado de definição para a transição exata entre as sessões. Contudo, podemos apontar três fatores estruturais para análise via espectromorfologia (Smalley, 1997):

- Ataque singular: Este é um impulso momentâneo de energia. Duas fases do tempo são mescladas em uma - há um início repentino que também é o fim. Não temos tempo suficiente para ouvir qualquer mudança apreciável na energia espectral, à medida que o som se move rapidamente até sua conclusão. Não há fase contínua. A consciência está focada na energia de ataque.

- Ataque/Decaimento: $\mathrm{O}$ ataque é prolongado por ressonância. $\mathrm{O}$ começo e o fim estão presentes, e pode haver uma orientação de continuação se percebermos que o som está sendo estendido em um nível consistente antes que decaia. 
MUSICA THEORICA Revista da Associação Brasileira de Teoria e Análise Musical 2019,

- Contínuo gradual: Neste arquétipo, todas as três fases estão presentes. O início começa gradualmente como se estivesse crescendo e termina gradualmente como se estivesse desaparecendo. No meio, o som é mantido por um tempo.

\subsubsection{Estruturação}

Consideramos alguns fatores para a análise eletroacústica de FPtoR. É relevante ressaltar que a estruturação de um trabalho eletroacústico não segue os parâmetros da música tonal. Isso se deve ao fato de que toda a estruturação da música tonal está associada a padrões de notas que geram pequenas estruturas, frases, períodos e sessões. Essa perspectiva de domínio da nota conceitual não se mantém na proposta eletroacústica. Nesse sentido, gestos e texturas são os principais fatores de uma análise espectromorfológica. ${ }^{3}$ Dessa maneira, Smalley explica:

[...] Não existe um tipo permanente de organização hierárquica para todas as músicas eletroacústicas, ou mesmo em um único trabalho. Sem dúvida, existem níveis estruturais, mas eles não precisam permanecer consistentes em número ao longo de uma obra, e um único nível não precisa ser executado permanentemente durante toda a extensão da obra. Por exemplo, pode-se detectar três ou quatro níveis em uma parte de um trabalho e menos ou mais em outra parte; uma seção de um trabalho pode compreender uma hierarquia clara de pequenos grupos de unidades, enquanto outra seção pode ser um todo muito maior, indivisível e de nível superior (Smalley 1997, p. 114).

Assim, distribuiremos algumas funções descritivas estruturais que nos ajudarão na análise proposta por Smalley (1997):

1) Início - Saída/Emergência/Anacrusis/Ataquel

2) Continuidade - Passagem/Transição/Prolongamento/Manutenção/

3) Término - Chegada/Desaparecimento/Fechamento/Liberação/Resolução.

É relevante mencionar a questão das obras que se desenvolvem gradualmente ou por processos de crescimento. Smalley propõe algumas possibilidades para descrições dessas condições:

\footnotetext{
${ }^{3}$ Obviamente, o processo nota pode se recorrente em uma peça eletroacústica, mas caso isso ocorra, existem outros métodos de análise que podem ajudar no trabalho.
} 
- Movimento Unidirecional: fornece um exemplo simples. Em um contorno lento e ascendente, podemos assumir uma variedade de resultados, mas em alguns casos, não há resultados. Esse movimento pode desaparecer a qualquer momento, pode aumentar a riqueza, levando a um ponto de impacto; pode ser absorvido por outros eventos; pode mudar a direção, transformando-se e etc.

- Movimento Recíproco: o movimento em uma direção é equilibrado por um movimento de retorno. Oscilação e ondulação, que são variações de contorno, podem ser aplicadas a movimentos texturais internos, bem como a descrições externas de contorno. As parábolas são geralmente mais gestuais, uma classe de trajetórias curvas.

- Movimento Centralizado: É expressa por reciclagem espectromorfológica, dando uma impressão de movimento relacionado a um ponto central. Isso pode ser alcançado apenas através de variações espectromorfológicas, mas geralmente é auxiliado pelo movimento espacial.

- Movimentos Bi-multidirecionais eles estabelecem expectativas e a maioria tem um senso de movimento direcionado. Eles podem ser considerados como tendo tendências gestuais e texturais e podem ser grandes estruturas. Eles podem aparecer como: aglomeração (acumulando-se em uma massa) e dissipação (dispersão ou desintegração).

\subsubsection{Textura}

Geralmente associado a movimentos bi-multidirecionais, usaremos algumas notas de movimento nessas unidades que podem contribuir para ações descritivas. Smalley sugere quatro subdivisões que podem ser mantidas em movimentos de continuidade ou descontinuidade: evaporação, afluir, convolução e turbulência. Entre esses comportamentos texturais, encontramos três estratégias capazes de gerenciar movimentos: interação, granulação e sustentação. Todas as três estratégias permitem uma ampla gama de possibilidades de aceleração ou redução. 
MUSICA THEORICA Revista da Associação Brasileira de Teoria e Análise Musical 2019, v. 4, n. 2, p. 182-207 - Journal of the Brazilian Society for Music

\subsubsection{Nota, Nó e Ruído}

De acordo com a proposta espectromorfológica, é necessário o entendimento de três graus variados de som encontrados em trabalhos eletroacústicos. A nota, o nó e o ruído. A nota está associada a um aspecto de intervalo, sendo adequado para medição de frequência, e sua determinação em Hertz (Hz) é possível. O ruído estaria na ponta inversa em relação a nota. Ou seja, devido sua complexidade sua análise se torna, via medição em $\mathrm{Hz}$, improvável. No entanto, de acordo com Smalley (1997), podemos adicionar descrições semânticas para auxiliar na análise de ruído. Sendo inicialmente uma definição qualitativa: rugosidade sem granulação e granularidade. Entre esses dois conceitos, podemos entender que o ruído pode ser tão espesso que sugere um aspecto multimodal como a rugosidade e ser quebrado em pedaços através da construção de uma macro unidade. A segunda definição está relacionada à densidade ou saturação do som. Esse tipo de condição sonora está relacionado à compressão espectral, ou seja, uma área do espaço espectral é compactada de tal forma que a percepção do tom é impossível. Além disso, isso pode ocorrer quando o espaço espectral é preenchido pelos contornos ativos de movimentos torcidos e turbulentos.

Entre a nota e o ruído, encontramos o nó. O nó seria uma estrutura com recursos ruidosos, mas que podem ser medidos em uma escala baseada em $\mathrm{Hz}$. Obviamente, essa medição às vezes não consiste em uma orientação perfeita, mas é suficiente para integrar aspectos de harmonicidade 4 e inarmonicidade em relação às notas. De um modo geral, podemos usar aspectos ruidosos como saturação/granulação associados aos aspectos frequenciais.

\subsubsection{Espaço Espectral}

O espaço espectral é definido pela distância entre os sons graves e agudos. $\mathrm{Na}$ análise espectromorfológica, são utilizados quatro tipos de descritores qualitativos que ajudam a entender o espaço espectral:

\footnotetext{
${ }^{4}$ Harmonicidade - aspecto ligado à organização intervalar baseado em vibração de cordas e colunas de ar. Inarmonicidade - aspecto ligado a ressonância dos materiais, podem migrar entre ruído e nota, gerando ambiguidade.
} 
1) Inanidade $5 /$ Plenitude - se o espaço é extensivamente coberto e preenchido, ou se as espectromorfologias ocupam áreas menores, criando grandes lacunas, dando uma impressão de vazio e talvez isolamento espectral.

2) Difusão/Concentração - se o som é espalhado ou disperso pelo espaço espectral ou se é concentrado ou fundido em regiões.

3) Afluência $/$ Interstícios - a estratificação do espaço espectral em afluentes estreitos ou amplos, separadas por espaços intermediários.

4) Sobreposição/Cruzamento - invasão do espaço espectral, movimento com alterações de região. Isso está diretamente relacionado aos processos de movimento e crescimento.

Ainda neste tópico, Smalley indica que as variações de possibilidade de descritores de espacialidade são diversas, permitindo muitas possibilidades de interpretação e considerações. No entanto, dois pontos parecem ser os mais relevantes, a escuta no espaço e a proposta de espaço composto. Escuta no espaço refere-se ao processo de reflexão sonora no ambiente e reconstrução espectral da fonte da audição. Vários fatores são considerados aqui: fontes fisiológicas de recepção estéreo, reflexão interna ou externa, dissipação/contenção de ondas de frequência no ar e assim por diante. $\mathrm{O}$ segundo ponto seriam as propostas imaginadas antes da performance sonora, considerando o uso do espaço como fator estrutural na construção do trabalho. Seis pontos podem ser destacados:

1) Configuração Espacial Única - A configuração exclusiva tem dois aspectos. Um trabalho pode ser definido em um único tipo de espaço que o ouvinte está ciente desde o início. Por outro lado, diferentes aspectos de um espaço podem ser revelados ao longo do tempo. A conscientização espacial é cumulativa, e o ouvinte acaba percebendo que existe uma topologia espacial global na qual todo o trabalho se encaixa.

\footnotetext{
${ }^{5}$ tradução livre do autor - Inanidade - referente a vaziez de matéria, conteúdo ou atividade; vacuidade. Original: Emptiness

6 tradução do autor.
} 
2) Múltiplas Configurações Espaciais - Durante todo o trabalho, o ouvinte está ciente dos diferentes tipos de espaço que não podem ser resolvidos em uma única configuração.

3) Simultaneidade Espacial - Dois ambientes complexos separados por características singulares (granulação e objetos gravados, por exemplo), mas que ocorrem temporalmente ao mesmo tempo. O ouvinte está ciente de ambos os espaços.

4) Simultaneidade Espacial Implícita - A simultaneidade implícita ocorre quando o ouvinte permanece ciente da existência de um espaço em sua ausência. Isso pode ocorrer, por exemplo, quando espaços contrastantes são intercalados e alternados (interpolação espacial), dando a impressão de simultaneidade, mesmo que os espaços sejam apresentados sucessivamente.

5) Passagem espacial - A passagem entre espaços pode ser súbita (passagem interrompida), intercalada repetidamente (passagem interpolada) ou mais gradualmente mesclada (passagem graduada).

6) Equilíbrio espacial - O equilíbrio relativo entre tipos de perspectiva e textura espacial na obra permite enfatizar mais um tipo de espaço do que outro, criando alternâncias ou trocas recíprocas entre espaços.

\subsection{Espaços Paradoxais}

Segundo Coelho de Souza (2013), a proposta de espaços paradoxais se revela uma estratégia considerável para a composição eletroacústica. Em sua abordagem, o autor propõe repensar o aspecto lógico existente ao ouvir certos materiais. Ou seja, devido às possibilidades de criação de material sonoro eletrônico e/ou processamento de som, o compositor seria capaz de desenvolver referências paradoxais, nas quais é mais provável que as fontes sejam notáveis no mesmo ambiente ou na mesma temporalidade. Nesse sentido, Coelho de Souza (2013) conceitua uma distorção do aspecto da Simultaneidade Espacial (Smalley 1997), produzindo "meta-espaços" que coexistem em similaridade ilógica e de comportamento semelhante.

Relata o autor: 
Outras tantas cenas virtuais surreais podem ser inferidas dos sentidos tópicos dos sons utilizados na peça. O espaço subterrâneo das vozes monstruosas, povoadas de água que gotejam por todos os lados, tem um tempo largo de reverberação incompatível com outros eventos que ali ocorrem, como fragmentos instrumentais que soam secos e próximos, assim como ruídos indistintos que caminham de um lado para outro, perdendo-se no infinito ou aproximando-se do receptor. A coexistência nesses espaços paradoxais de objetos sonoros que portam tempos de reverberação diferentes, fases sonoras dinamicamente variáveis, e intensidades flutuantes que sugerem distância ou proximidade, constitui uma interpretação metafórica das tópicas que sugerem sentidos espaciais, o que, a meu ver, constitui um dos artifícios idiomáticos mais engenhosos que se pode elaborar a partir das técnicas eletroacústicas (Coelho de Souza 2013, p. 34).

Em FPtoR, acreditamos que esta proposta seja eficaz para uma análise de como os aspectos da paisagem sonora podem se tornar uma paisagem sonora de espaços paradoxais.

\section{Five Places to Remember}

Five Places to Remember (FPtoR) produzida em 2008, produzido em 2008, refere-se ao processo imaginário do compositor sobre diversas paisagens sonoras de cinco cidades do mundo: Praga, Berlim, Bogotá, Paraty e Bruxelas. Nesta análise, utilizamos apenas três das cinco peças: Paraty, Bruxelas e Praga. Não temos fonte de notação para o trabalho, utilizando apenas a observação auditiva e o sonograma para análise. Dois fatores principais foram observados nas três obras e conceituados nessa análise: 1) processo rítmico electroacústico - conceito que trabalha o uso de estratégias técnicas na música eletroacústica para desenvolver parâmetros rítmicos complexos. 2) Marcadores de Som Transmutados (MST) conceito baseado na referencialidade para representações de características ambientais. Os conceitos propostos aqui serão melhor discutidos nas discussões finais.

\section{Five Places to Remember (Bruxelas)}

Em FPtoR (Bruxelas), podemos resumir a peça em uma proposta em que ocorre uma transformação gradual do material. Ou seja, um objeto de origem reconhecível se torna uma abstração de fonte irreconhecível. O conceito de ambiente paradoxal é observável principalmente na sessão $\mathrm{A}$, onde as vozes humanas são amplificadas com o uso de processamento eletrônico, criando uma 
textura complexa que dificilmente poderia ser atribuída às micro-defasagens naturais. De maneira macro, encontramos uma generalização nos movimentos centralizados, buscando uma transformação significativa do todo, sendo o processamento baseado na espacialidade uma diretriz fundamental. A textura possui características de granulação com aspectos complexos, levando a acelerações e reduções de material. Há um predomínio por características ressonantes, permitindo o estreitamento do material para criar novos objetos através de transformações. Em Bruxelas, o conceito processo rítmico eletroacústico (PRE) é observado. Podemos apontar algumas estratégias utilizadas para a geração dp PRE como: espacialização, recortes de material e técnica eletroacústica "triângulo". ${ }^{7}$ Acreditamos que o conceito PRE pode ser melhor desenvolvido, no entanto, em nossa análise, ele aborda os aspectos gerais para a explicação do pensamento do compositor.

\section{Descrição em linha temporal:}

$0^{\prime}: 00^{\prime \prime}-0^{\prime}: 46^{\prime \prime}$ - A peça começa com um recitativo, onde as vozes estão sendo processadas lentamente (delay). Essa fusão de material propõe uma geração complexa de informações, que podemos definir como ruído. No entanto, como as fontes são múltiplas (replicadas ou não), o ruído leva a um resultado textural.

0':33" - Menos textura sonora, diminuindo as condições de ruído e introduzindo mais propriedades de nó.

0':48" - Mudanças significativas no contexto textural, trazendo em primeiro plano a condução da voz in natura. Maior percepção dos nós e linearidade na representatividade da voz. Embora no espectrograma possamos encontrar uma complexidade devido à construção da textura, parece claro para nós a noção de uma voz acompanhada de textura. É interessante ressaltar essa premissa, onde a escuta reduzida é proposta na textura, mas em contraposição a parte vocal, conduzindo a um total reconhecimento da fonte [processo similar ao proposto em Stockhausen em "Gesange der Jünguelinge" (Coelho de Souza 2013)].

1':03" - Observamos uma eliminação quase completa da textura, deixando clara pela primeira vez a fonte do idioma usado, o francês.

\footnotetext{
7 Termo não acadêmico que trata da utilização de técnicas de recortes e inversões de padrões dinâmicos, que visualizados no sonograma remetem em triângulos.
} 
1':13" - Fim da seção A. O coro é novamente introduzido, como a proposta de textura/ruído. No entanto, há a introdução do processamento de autopan, criando movimentos rápidos de espacialização. Não há alteração da organização das vozes humanas, mas o processamento remete a um aspecto rítmico causado pelo "movimento" direita x esquerda do som (estéreo), criando uma estrutura contrapontística de PRE contra textura.

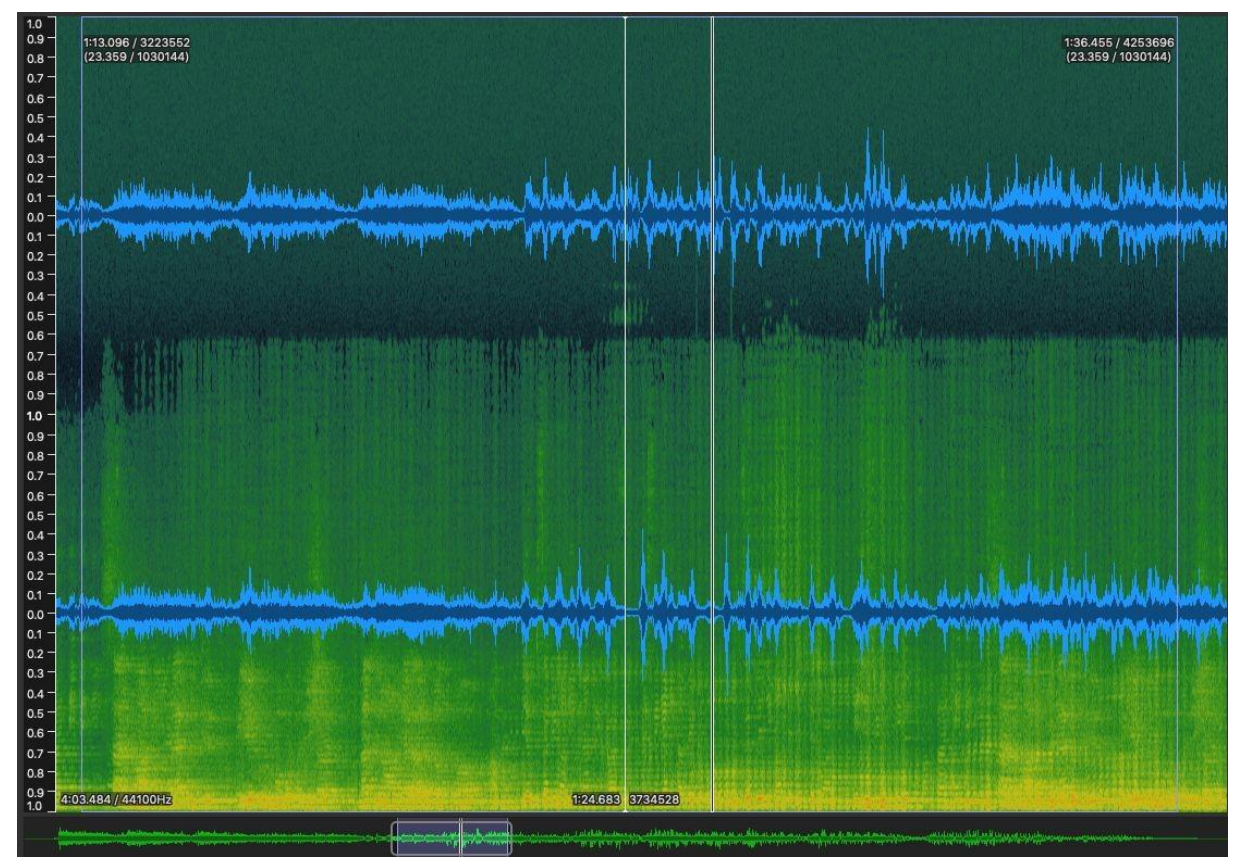

Figura 1: Utilização de processamento para geração de padrões rítmicos complexos

$1^{\prime}: 51^{\prime \prime}$ - Encontramos um retorno à voz principal. A partir desse ponto, o autopan começa a potencializar a condição de repetição. Ou seja, as variações na quantidade e tipos de acentos rítmicos. Não há uma regularidade na ocorrência nos acentos, mas é perceptível que o material usado para os movimentos de panorâmica também está relacionado à voz. No entanto, não é possível apontar claramente se o material é o mesmo que o usado anteriormente.

2':00" - Observamos a introdução de mais um objeto sonoro, que também se relaciona com o processamento de vozes e do autopan: o uso do processamento de pitch shifting. Ao contrário do que aconteceu anteriormente, o plano de voz não processado se move lentamente para o fundo enquanto o objeto processado está em primeiro plano.

2':30" - Observamos um aspecto de baixo contínuo produzido por um objeto nó. Esse baixo contínuo parece vir do alongamento do material vocal solo. 
MUSICA THEORICA Revista da Associação Brasileira de Teoria e Análise Musical 2019,

v. 4, n. 2, p. 182-207 - Journal of the Brazilian Society for Music

Como se o processo tivesse sido temporalmente dilatado, e a referencialidade da fonte tivesse sido removida.

3':30" - Fadeout que progride até o final da peça.

\section{Five Places to Remember (Paraty)}

Podemos subdividir a peça em três seções principais, sessão A (banda), B (fogos de artifício) e $\mathrm{C}$ (textura granular). A peça começa com referência a bandas marciais de cidades do interior do Brasil, neste caso Paraty. A seção B segue um momento de referência aos fogos de artifício e termina na seção $C$, onde encontramos um desenvolvimento de textura pontilhista e granular com pequenos enxertos de materiais remanescentes da seção B.

A peça indica um desenvolvimento de uma fonte reconhecível para um resultado

eletroacústico textural. O ponto de conexão entre esses dois estágios seria o uso do objeto do tipo fogos de artifício. Embora seja coerente acreditar que o objeto é criado via síntese sonora, existe uma semelhança de relacionamentos, afinal, em ambientes onde as festividades ocorrem, pode haver fogos de artifício.

É relevante ressaltar nosso conceito, proposto neste texto, de Marcadores de Som Transmutados (MST). A concepção de referencialidade da peça está relacionada a pontos que, para o compositor, representam esse ambiente. Ou seja, o compositor pode propor um processo de organização determinando se os processos serão mais ou menos referenciais/abstratos. Essa relação de similaridade entre o objeto gravado (fogos de artifício) e o objeto sintético simulado, promove uma conexão com a organização da peça, no entanto, não garante que haverá a mesma condição de organização da escuta. Durante a análise, foram necessárias várias escutas atentas e ferramentas de análise (como a visualização do espectrograma) para alcançar essa percepção. É necessário um maior desenvolvimento da proposta para gerar uma cultura de escuta diante dessa prática entre objetos referenciais e abstratos.

Outro fator a ser destacado é a relação rítmica/percussiva do compositor, utilizando ferramentas e materiais eletroacústicos para essa estruturação, conforme observado na seção B (PRE). Como se vê neste texto, o uso de ferramentas eletroacústicas para geração de materiais e organizado como potencialidades rítmicas parece ser uma possibilidade técnica a ser expandida que possa contribuir com práticas eletroacústicas e práticas ecológicas. 


\section{Descrição em linha temporal:}

0':00" - Introdução de objetos gravados, estilo de paisagem sonora, introduzindo um tópico de "banda" com alturas perceptíveis (padrão notas), no entanto, variando em quartos de tom acima ou abaixo. Induz a prerrogativa de uma modificação do pitch shifter, simulando as dilatações que ocorrem nas gravações em fita. Observamos o uso do processamento de autopan para organizar a espacialidade do processo.

0':27"- O objeto fogos de artifício a parece pela primeira vez, sendo observado dentro do objeto banda. Os mesmos processos descritos acima são observados.

0':30" - O objeto banda é mostrado no plano frontal, propondo um aspecto de proximidade.

0':47" - No início da construção da seção B é observado uma fusão entre o som inicial do objeto fogos de artifício e um objeto produzido em síntese FM que aumenta o ataque do envelope. Não está claro para nós se a construção é de fato sintética ou um objeto de percussão gravado (como um bumbo ou surdo). Portanto, assumiremos a premissa de síntese, pois oferece material suficiente para a discussão proposta aqui.

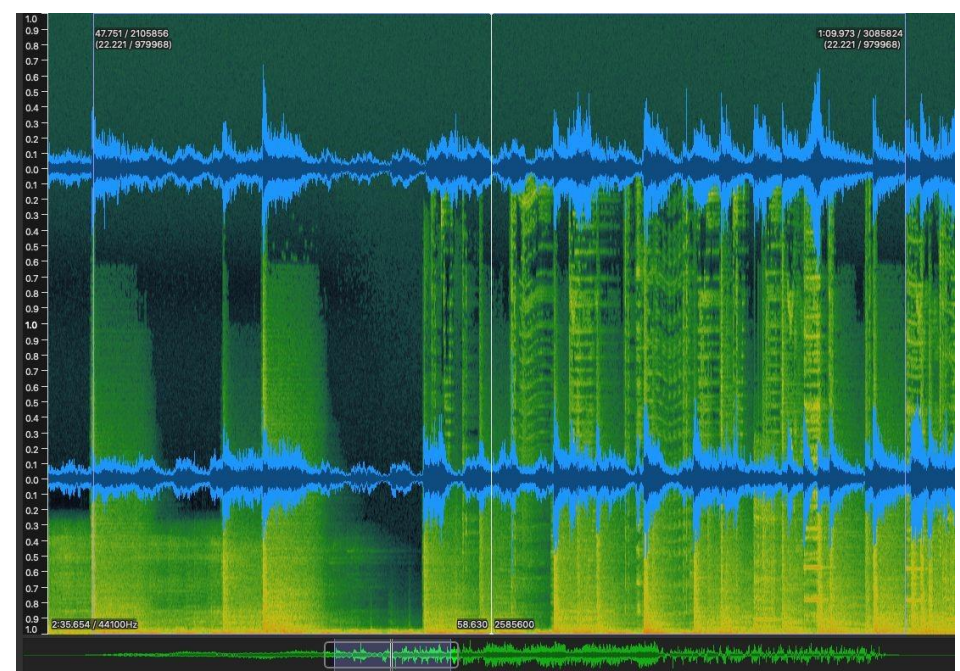

Figura 2: Fusão entre dois objetos sonoros caracterizando pela estratégia do Processo Rítmico Eletroacústico (PER)

0':56"- Novos materiais eletrônicos são introduzidos. Síntese granular e espacialização (provavelmente autopan) são os recursos mais utilizados. Essa estrutura parece criar um desdobramento de referências ao objeto fogos de artifício. Em geral, observamos destaques para a síntese utilizada como efeito percussivo com amplitudes maiores, dispostas em um plano frontal. A síntese granular é, 
MUSICA THEORICA Revista da Associação Brasileira de Teoria e Análise Musical 2019, v. 4, n. 2, p. 182-207 - Journal of the Brazilian Society for Music Theory and Analysis@ TeMA 2019 - ISSN 2525-5541

portanto, um ponto de referência da "reminiscência" dos fogos de artifício "explodindo". Nesse sentido, podemos argumentar que o compositor tenta recriar o som dos fogos de artifício como um todo, enfatizando o aspecto rítmico/percussivo que poderia existir nas explosões. Embora encontremos características de construção do aspecto do ruído, existe uma premissa de nó que guia os objetos eletrônicos.

1':16" - O ponto culminante da peça, tanto em uma diretriz de desenvolvimento quanto em complexidade. São utilizados os dois principais objetos sonoros eletrônicos da peça, a "percussão" (objeto criado para simular as primeiras explosões) e os sons granulares (objeto criado para simular explosões subsequentes). A alternância dos dois objetos juntos como uma rápida transição da espacialidade (direita x esquerda e vice-versa) confere maior complexidade para a peça. É importante ressaltar que, embora o formato da peça tenha migrado de fontes reconhecíveis e tenha se tornado um construto com características de escuta reduzida, o modo como a transformação é conduzida, associada ao aspecto rítmico de pregnância, propõe uma consistência formal. As relações imaginadas pelo compositor nesta seção da peça exemplificam nosso argumento sobre pontos de referência.

1':31"- Observamos na mesma seção algumas variações nos objetos percussivos/granulares descritos anteriormente. Nesse sentido, há uma transformação significativa em harmônicos com taxas de $15.245 \mathrm{~Hz}$ a $16.408 \mathrm{~Hz}$. No entanto, as variações mostram pouco impacto no contexto geral. Aparentemente, o compositor não se concentrou em uma perspectiva textural, embora às vezes ela ocorra, mas em uma diretiva de plano em que os eventos ocorrem por atraso (isto é, com uma ênfase na espacialização). Isso gera uma construção mais clara dos objetos, ou seja, existe uma maior possibilidade de perceber suas origens e onde eles são transformados.

1':49" - Os mesmos objetos mencionados acima retornam, com maior pregnância para o material granular. Existem ataques percussivos, mas que apenas pontuam a sessão. O material é determinado pelo caráter técnico de autopan. As mesmas construções harmônicas com taxas de frequência graves reaparecem com uma amostragem mais altas, de $7.622 \mathrm{~Hz}$ para $9.948 \mathrm{~Hz}$.

2':00" a 2':35" - Objetos granulares dominam esta sessão final. Há uma diminuição na ocorrência de materiais, ou seja, os grãos são cada vez mais 
espaçados. Pequenos elementos eletrônicos são encontrados, aparentemente como um recurso de finalização (fadeout).

\section{Five Places to Remember (Praga)}

O trabalho é subdividido em duas partes gerais, sendo que a seção B possui variações que permitem subdivisões. Na forma macro, temos grandes formas texturais com movimentos bi-multidirecionais, permitindo trocas de materiais, dissoluções e agregações de objetos, proporcionando um fluxo contínuo. A espacialidade é governada principalmente pelo caráter de sobreposição ou cruzamento, conduzindo invasões e alterações espectrais, admitindo um caráter de crescimento.

Em comparação com as outras peças analisadas neste texto, encontramos no FPtoR (Praga) uma condição mais complexa. A referencialidade de sítio específico (site specific) é abandonada, sugerindo uma mudança drástica e induzindo o ouvinte a considerar o material da seção B como algo novo. No entanto, à luz desta análise, destacamos uma possível aplicação para obras ecológicas, que consiste em um reconfiguração dos materiais de paisagem sonora com o intuito de gerar uma alusão à esta ecologia fora do contexto geral (ruído, passos, vozes, etc), mas através de elementos que o compositor julgou relevante para representar a localidade. Truax (2002) usa fatores semelhantes em obras baseadas em síntese granular. Ou seja, se propõe a expandir as propriedades de paisagem sonora através do uso da síntese. No entanto, em FPtoR, há um pensamento menos ecologicamente criativo (Keller 2012) e mais voltado ao pensamento eletroacústico.

Outro fator relevante é o destaque para o objeto estalo, que é apresentado na peça como um dos pontos estruturais. Em um curto momento, durante a sessão B, podemos observar uma maior complexidade diante as relações de referencialidade. Assim, propomos um conceito para tentar exemplificar a ideia: os Marcadores de Som Transmutados (MST). Os MSTs seriam objetos diretamente ligados à referencialidade de um local, seguindo um caminho contrário às propostas de escuta reduzida. Nesse sentido, os MSTs são unidades de material extremamente pregnante que vinculam a escuta a significados não abstratos, por exemplo, sons de rios, chuva, trovões etc. O que o compositor propõe fazer em PTtoR (Praga) é coletar MSTs e usá-los como eixos centrais que irão se 
MUSICA THEORICA Revista da Associação Brasileira de Teoria e Análise Musical 2019, v. 4, n. 2, p. 182-207 - Journal of the Brazilian Society for Music

transformar, perdendo sua referencialidade direta (perda de pregnância), visando um aspecto abstrato. Podemos inferir, portanto, que a construção de obras neste formato terá uma organização significativa, através dos MSTs como eixos fundamentais, permitindo migrações ou misturas de materiais mais ou menos referenciais.

\section{Descrição Analítica na Linha do Tempo}

0':00" - A peça inicia com uma paisagem sonora de aeroporto/ferroviária ou rodoviária. Essa paisagem sonora possui uma ampla gama de sons que constituem uma textura complexa que envolve passos, vozes, sinos, etc.

0':02"- Encontramos o objeto principal da peça, um típico sino utilizado para informações de ambientes coletivos, o qual chamaremos de objeto sino para facilitar a análise. O objeto sino consiste em três notas: Dó 5, Lá, 4 e Mi, 4.

0':03"- Neste ponto, a nota Mi, é acrescida por um nó grave, em torno de $45 \mathrm{hz}$, que chamaremos de objeto rugoso. O nó possui características de síntese FM e maior harmonicidade/periodicidade que as outras três notas. Isso é, se mantém até doze segundos, enquanto as notas aparecem nos três segundos e desaparecem a quatro segundos.

0':05" - Novamente a sequência de três notas reaparece e, novamente na nota Mi bemol, é introduzido um objeto semelhante a um sino. Esse novo objeto (sino sintético) é construído sobre a síntese FM e tem uma harmonicidade com o objeto sino, porém sua construção é mais próxima do nó do que das notas.

0':08" - Um pequeno elemento é introduzido. Usaremos o termo objeto estalo. Esse objeto aparece inicialmente nos sete segundos, dentro da paisagem sonora, mas nos oito segundos ele reaparece sinteticamente construído.

0':19" - O objeto estalo reaparece, no entanto, em uma estrutura rítmica utilizando defasagens de ataque entre as faixas da direita e esquerda. Novamente, como em outras peças analisadas, o compositor usa a premissa de espacialização para criar processos rítmicos/percussivo em trabalhos eletroacústicos.

0':29" - O objeto rugoso reaparece no final da "sessão estalo", indicando o final da sessão A da peça. É relevante enfatizar que todo o desenvolvimento do trabalho é gerado pelos materiais emergentes desta sessão. A partir do segundo vinte e nove, encontramos apenas variações dos objetos, alterando as técnicas 
eletroacústicas (inversão, espacialização, triângulo) ou processamento (granulação, reverberação, delay).

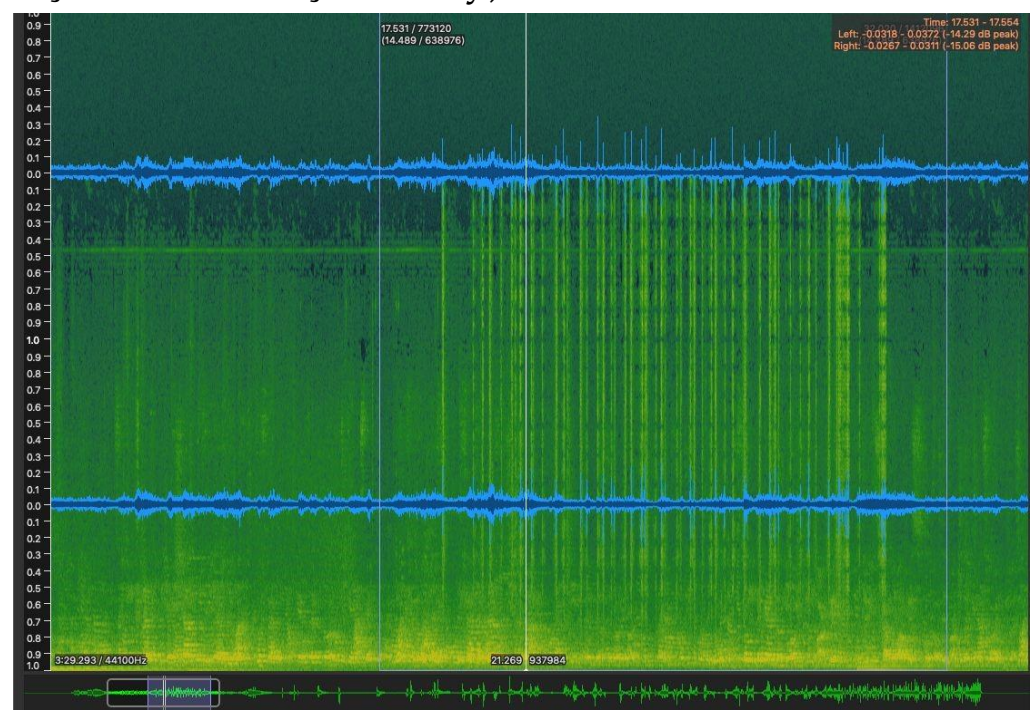

Figura 3: Demonstração da sessão "estalo"

0':35" - O objeto sino reaparece variável, o que significa que há uma diminuição no tempo entre os intervalos em que o objeto aparece, criando um parâmetro de aceleração.

0':40" - O objeto rugoso reaparece, encerrando a sessão A. A reexposição define a mesma taxa de frequência, em torno de $45 \mathrm{hz}$, porém com a modificação do processamento, introduzindo mais reverberação. Essa reexposição do material está alinhada com a atividade anterior, ou seja, atuando como um pedal no objeto sino. O objeto sino reaparece em sua forma sem alteração.

0':48" - A sessão B começa. Há quase uma conclusão da representatividade paisagem sonora. A sessão é aberta com o objeto estalo, no entanto, é observado o processamento de síntese granular e um maior tempo de sustentação e decaimento. 
MUSICA THEORICA Revista da Associação Brasileira de Teoria e Análise Musical 2019, v. 4, n. 2, p. 182-207 - Journal of the Brazilian Society for Music Theory and Analysis@ TeMA 2019 - ISSN 2525-5541

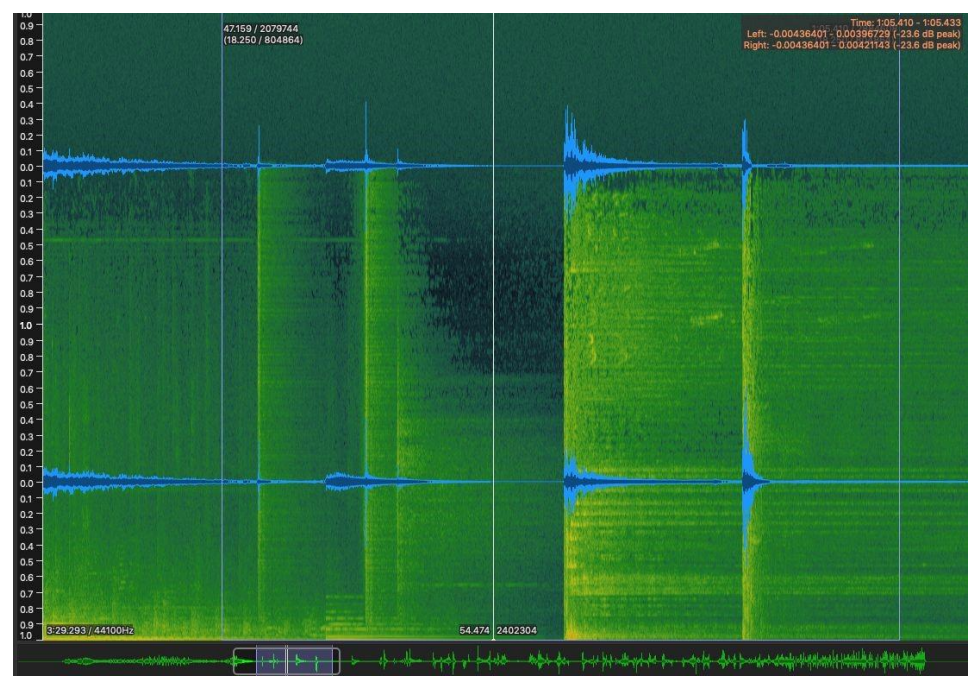

Figura 4: Início da seção B

0':49" - O objeto sino reaparece, mas agora encontramos um novo objeto, uma gravação de sino. Essa avaliação pode ser confirmada pela diferença entre as parciais harmônicas, mais complexas do que as produzidas via síntese.
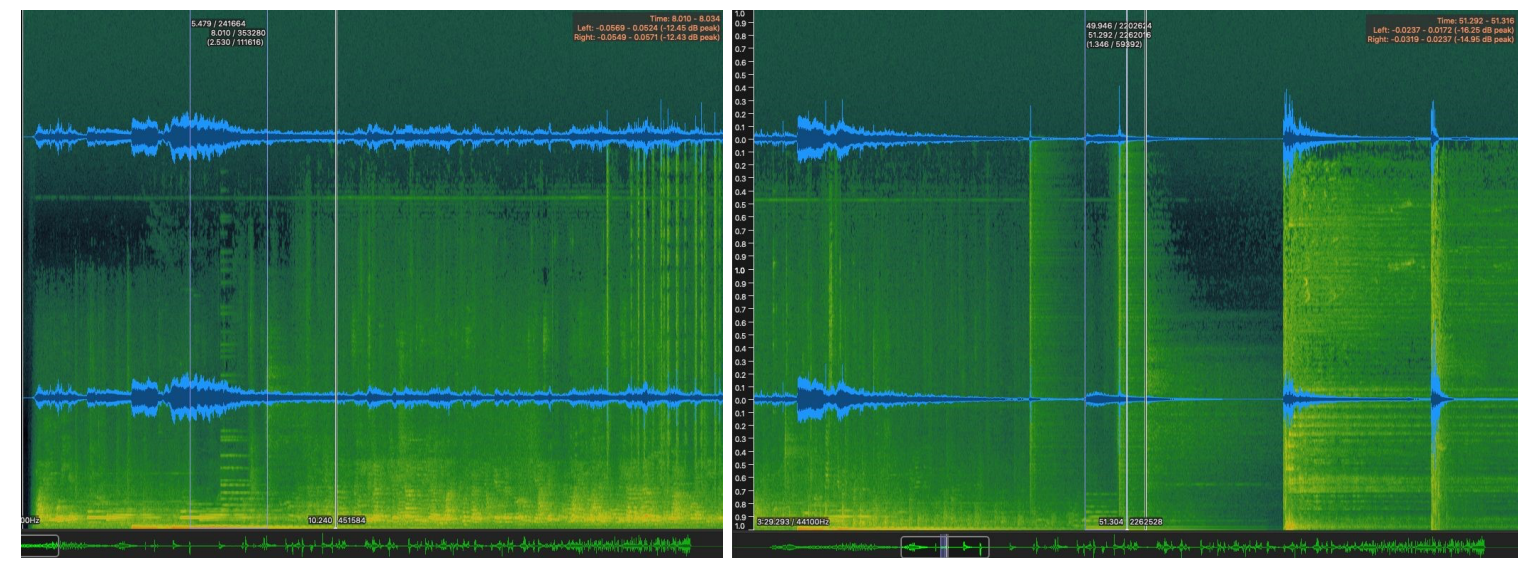

Figura 5: Diferenciação de parciais de sino entre construção via síntese (esquerda) e objeto gravado (direita)

0':51" - O objeto estalo reaparece com processamento granular e maior sustentação e decaimento. O efeito delay também é adicionado.

0':56" - Objeto estalo novamente é apresentado com os mesmos procedimentos citados anteriormente, mas são adicionadas maior amplitude e granulação. Esta pequena sessão induz um aumento de complexidade em relação às primeiras exposições.

1':09" - Inicia-se uma sessão com as mesmas características do objeto estalo. Podemos observar processamentos como granulação, reverberação e 
espacialidade (autopan). Embora o som esteja vinculado ao objeto estalo, o que é observado são trechos de materiais gravados recortados, sendo organizados com a técnica de "triângulo". Essa técnica é interessante, pois utiliza os "triângulos" associados à espacialização, criando um distúrbio de percepção. A complexidade está na perda de referência do que seria o movimento sonoro esperado. Novamente, o compositor propõe o uso de recursos baseados em MSTs para criar condições variáveis. O tipo de material parece ter sido retirado da primeira sessão A (paisagem sonora). Não podemos afirmar isso com certeza, devido à enorme quantidade de processamento na sessão. No entanto, usando o processamento de inversão para esta análise, conseguimos reconhecer alguns objetos com propriedades vocais que parecem estar associadas ao material inicial da peça.

1':01" até 2':05" - Toda a sessão B não parece possuir algum outro apontamento importante que seja divergente da descrição acima. Devido à complexidade do material e às possibilidades limitadas de análise (sem relatórios ou manuscritos do compositor), apenas podemos sugerir questionamentos.

2':05" até 2':58" - Podemos considerar esse período como sessão B1. Embora tenha uma semelhança com os materiais da sessão $B$, há uma diminuição nos processamentos, embora seja possível reconhecer alguns parâmetros, como vozes humanas. Essa diminuição colabora com nossa tese de que a proposta da peça é desenvolver algumas estruturas básicas que sirvam de referência para o compositor e, assim, migrar entre fontes referenciais e não referenciais. Na sessão B1, a ausência de referencialidade não é tão evidente quanto na sessão B, permitindo exatamente esse jogo entre escuta reduzida e escuta referencial.

2':58" até 3':28" - Vamos considerar mais uma subdivisão da sessão B: a sessão B2. Isso ocorre devido a dois materiais que aparecem nesse período. Aos dois minutos e cinquenta e oito, observamos o retorno do objeto estalo, no entanto, quase sem processamento. Essa mesma referencialidade pode ser apontada em três minutos e dezoito segundos. Acreditamos que esta é uma evidência adicional de que o material da seção B é um objeto da sessão A processado e organizado por algum mecanismo de permutação, tendo a técnica de inversão/triângulo como principal suporte técnico. 


\section{Discussões Finais}

Ao propor a análise de Five Places to Remember, somos induzidos a utilizar o processo de composição de paisagens sonoras. No entanto, observamos que a estrutura se baseia mais na condição tradicional da composição eletroacústica do que na inserção de um aspecto ecológico. De fato, podemos apontar essa ausência de substancialidade em obras de caráter de paisagem sonora em geral. Provavelmente devido à falta de definição clara e aspectos consistentes da pesquisa, muitos compositores tendem a chamar trabalhos relacionados a locais ou sons específicos como paisagens sonoras, desconhecendo os processos desenvolvidos pelo WSP (descritos na introdução deste trabalho). FPtoR não é descrito no catálogo como obra do estilo paisagens sonoras, porém em uma descrição do material encontrado na internet, ${ }^{8}$ a nomenclatura é utilizada.

Embora o FPtoR tenha um pensamento focado na composição eletroacústica, sem uma preocupação específica com os conceitos de paisagem sonora, encontramos características relacionadas a ela. Schafer (1977) propõe o conceito de marcações sonoras (soundmarks), que consiste em definir apontamentos que representam paisagens sonoras como aspectos da representatividade. Por exemplo, em uma paisagem sonora, ao ouvir o som de um rio, o compositor pode usar a marca "rio" e, durante o curso da peça, pode reutilizar a marca "rio" para recuperar a referencialidade. $\mathrm{O}$ que observamos na estratégia FPtoR é uma abordagem semelhante, que conceituamos como Marcadores de Som Transmutados. Nessa abordagem, as marcações são quase subjetivas, afinal a transformação do som é tão drástica que a persistência da referencialidade na audição não prevalece. No entanto, podemos observar a consistência dessas características devido à análise espectromorfológica. Essa configuração permite várias estratégias e pode contribuir para o campo de práticas sonoras ecológicas.

Outro fator relevante é um processo técnico que, neste trabalho, foi conceituado como processo rítmico eletroacústico (PRE). Esse conceito gira em torno do uso de estratégias técnicas da música eletroacústica para desenvolver parâmetros rítmicos complexos. Como foi visualizado nos três trabalhos, o compositor utiliza recursos de espacialização, recortes do material entre outras técnicas para obter uma objetividade rítmica.

\footnotetext{
${ }^{8}$ https://www.filmschule.de/en/projects-films/five-places-to-remember/
} 
Essa estratégia foi observada tanto nas estruturas baseadas em síntese sonora (criando objetos sonoros semelhantes aos instrumentos de percussão) quanto nos modelos mais complexos, como a manipulação de materiais texturizados/ruidosos. Percebe-se que o uso dessa estratégia via síntese não oferece muita contribuição, pois não parece dilatar as possibilidades de composição eletroacústica, afinal, a gravação de instrumentos de percussão ou a performance ao vivo geram material mais interessante e complexo. No entanto, o uso do mesmo princípio, mas com elementos granulares e saturados, permite a exploração de um material complexo de maneira organizada e objetiva.

Finalmente, acreditamos que as duas contribuições apresentadas nesta análise, marcadores de som transmutados e processo rítmico eletroacústico fornecem material para futuras discussões sobre abordagens técnicas da prática sonora ecológica. Embora os conceitos tenham sido apresentados de maneira rudimentar, exigindo novas abordagens para considerar seu valor, parece possível incluí-los como recursos práticos para a composição eletroacústica.

Aquém desse fator, as abordagens espectromorfológicas de Smalley (1997), apoiadas nas notas de Coelho de Souza (2013), permitiram analisar obras com características divergentes, como FPtoR. Acreditamos que esse tipo de abordagem analítica funciona satisfatoriamente em obras ecológicas, fornecendo perspectivas relevantes.

\section{Referências}

1. Aliel, Luzilei. 2017. Ensaios sobre comprovisações em ecologia sonora: Perspectivas práticas e teóricas. Dissertação de Mestrado em Música. São Paulo: USP.

2. Arkette, Sophie. 2004. Sounds Like City. Theory, Culture \& Society 21, p. 159168.

3. Barreiro, Daniel; Keller, Damián. 2010. Composição com Modelos Sonoros: Fundamentos e Aplicações Eletroacústicas. In: Damián Keller e Rogério Budasz (ed.). Criação Musical e Tecnologias: Teoria e Prática Interdisciplinar. Goiânia: ANPPOM, p. 97-126. Disponível em: $<$ http://anppom.com.br/editora/Pesquisa_em_Musica-02.pdf>.

4. Chion, Michel. 1983. Guide des objets sonores. Paris, Buchet/Chastel.

5. Coelho de Souza, Rodolfo. 2013. Abstração e representação na música eletroacústica. Revista Vórtex, Curitiba, n. 1, p. 23-35. 
MUSICA THEORICA Revista da Associação Brasileira de Teoria e Análise Musical 2019, v. 4, n. 2, p. 182-207 - Journal of the Brazilian Society for Music Theory and Analysis @ TeMA 2019 - ISSN 2525-5541

6. Keller, Damián. 2012. Sonic Ecologies. In: A. R. Brown (ed.) Vol. Sound Musicianship: Understanding the Crafts of Music (p. 213-227). Newcastle upon Tyne, UK: Cambridge Scholars Publishing.

7. Schaeffer, Pierre. 1966. Traité des objets musicaux. Paris: Seuil.

8. Schafer, R. Murray. 1977. The Soundscape: Our Sonic Environment and the Tuning of the World. Rochester, Vermont: Destiny Books.

9. Schafer, R. Murray. 2001. A afinação do mundo. São Paulo: Ed. UNESP.

10. Schulte-Fortkamp, B.; Fiebig, A. 2006. Soundscape Analysis in a Residential Area: An Evaluation of Noise and People's Mind. In: Acta Acustica united with Acustica 92, p. 875-880.

11. Smalley, Denis. 1997. Explaining Sound Shapes. Organised Sound, v. 2, No. 2, p. 107-126.

12. Southworth, Michael. 1969. The Sonic Environment of Cities. In: Environment and Behavior, p. 49-70.

13. Payne, S. R., Davies, W. J., Adams, M. D. 2009. Research into the Practical and Policy Applications of Soundscape Concepts and Techniques in Urban Areas (NANR 200), Technical Report May.

14. Truax, Barry. 2002. Genres and Techniques of Soundscape Composition as Developed at Simon Fraser University. In: Organised Sound, v.7(1), p. 5-14.

15. Truax, Barry. 2001. Acoustic Communication. Ablex.

16. Truax, B.; Barrett, G. W. 2011. Soundscape in a Context of Acoustic and Landscape Ecology, Landscape Ecology 26(9), p. 1201-1207.

17. Westerkamp, Hildegard. 2002. Linking Soundscape Composition and Acoustic Ecology. In: Organised Sound, v. 7(1), p. 51-56. 